\title{
Assessment of Ballast Flying in the National Railway Network of Ethiopia
}

\author{
Fikadu Mengistu, Henok F. Gebregziabher \\ Awash-Kombolcha-Haragebeya Railway Project, Ethiopian Railways Corporation, Addis Ababa, Ethiopia \\ Email: fikadumengistu16@gmail.com, henok.fikre@aait.edu.et
}

How to cite this paper: Mengistu, F. and Gebregziabher, H.F. (2021) Assessment of Ballast Flying in the National Railway Network of Ethiopia. Engineering, 13, 420-429. https://doi.org/10.4236/eng.2021.137030

Received: June 6, 2021

Accepted: July 20, 2021

Published: July 23, 2021

Copyright $\odot 2021$ by author(s) and Scientific Research Publishing Inc. This work is licensed under the Creative Commons Attribution International License (CC BY 4.0).

http://creativecommons.org/licenses/by/4.0/

\begin{abstract}
One of the major problems in ballasted railroads is ballast flying, which is the projection of ballast particles from the at-rest position as the train passes over the track of a railway structure, mainly due to high speed. In this research, the possibility of railway ballast flying for the double track Addis-Adama section of the new Addis-Djibouti railway line is assessed by determining the major causes of ballast flying and applying Discrete Element Modeling (DEM) with the aid of Particle Flow Code (PFC3D) software. The analysis comprised of an impact load and ballast material behavior which were used to determine the vibrational speed of individual ballast particles. The governing result from the series of discrete element analyses performed by considering fouled ballast gradation with grain-size diameter of $22.4 \mathrm{~mm}$ gives rise to a ballast maximum vibrational speed of $0.014 \mathrm{~m} / \mathrm{s}$. Since the ballast vibrational speed for Addis Ababa-Adama line is less than $0.02 \mathrm{~m} / \mathrm{s}$ that is recommended by the literature, no ballast flight is expected under the present traffic and ballast conditions.
\end{abstract}

\section{Keywords}

Railway Track, Ballast Flying, Discrete Element Modeling, Ballast Vibrational Speed, Particle Flow Code

\section{Introduction}

Ethiopian Railways Corporation has planned to construct over five thousand kilometers of railroad in two phases; among which the new Addis Ababa-Djibouti line, which stretches more than seven hundred kilometers, is the major focus of this research. This railway corridor is the main corridor in the country for transporting import/export commodities. The route begins at Sebeta, in the southwestern parts of Addis Ababa, and runs eastwards to Nagad (front-port 
station of Djibouti). From this $752.7 \mathrm{~km}$ long electric traction route, about 670.7 $\mathrm{km}$ is in Ethiopia (from Sebeta to Dewenle) [1].

The first section of that corridor, from Addis Ababa/Sebeta to Adama, is a standard gage $(1435 \mathrm{~mm})$ railway (Figure 1), which is $110.5 \mathrm{~km}$ long with the maximum design passenger train speed of $160 \mathrm{~km} / \mathrm{h}$ and distance between the two centerlines of the double track is $4 \mathrm{~m}$. That section of the railway line was selected for this study since it is the critical section for ballast flying due to the effects of the superimposed speeds of trains using the double track section. The project area is very windy and it is part of the great east African valley, which makes it seismic hazard prone. Since it is one of the major rail networks in the country, it should be safeguarded from any rail track problems like ballast flying.
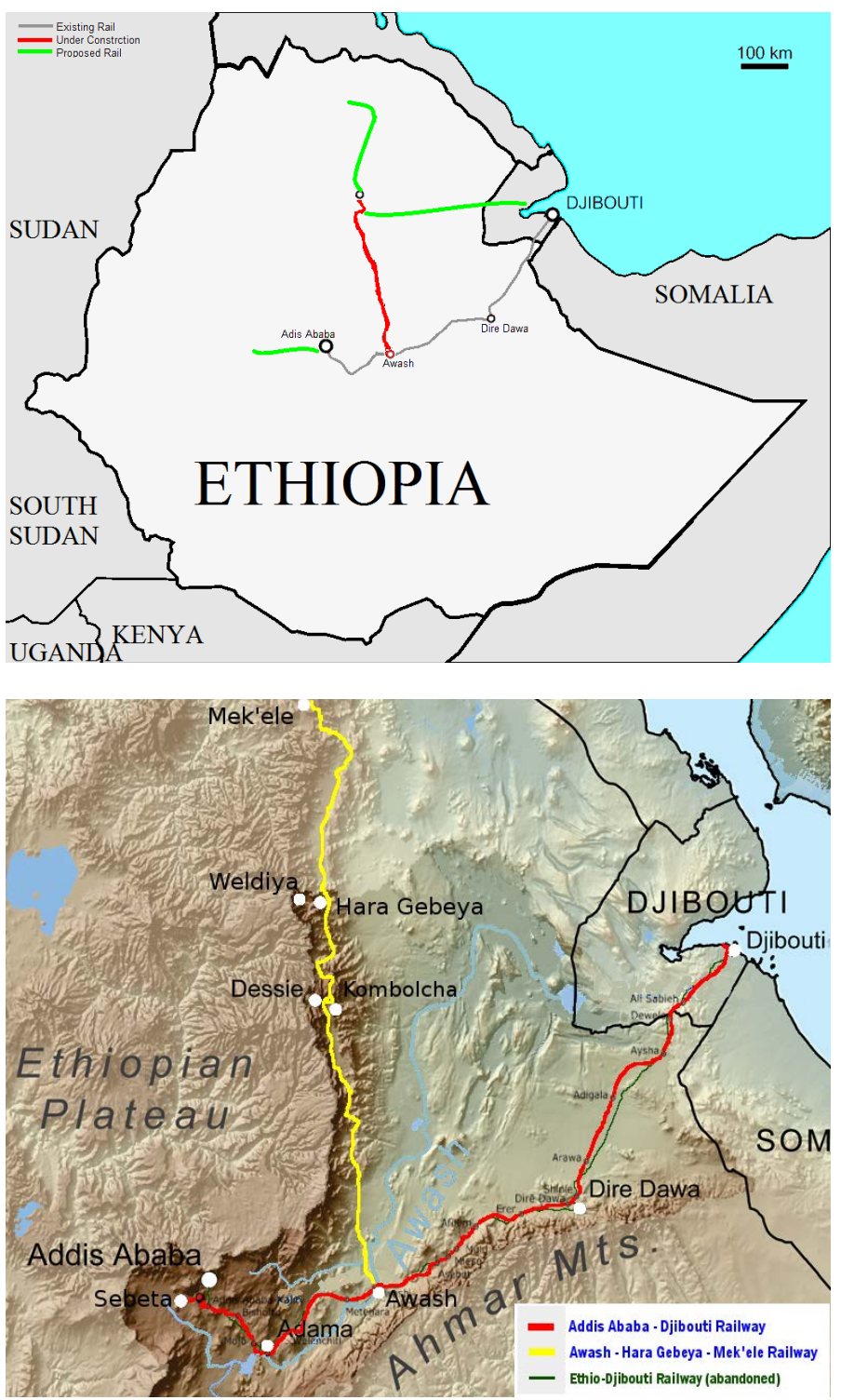

Figure 1. Map of Ethiopia with railway gridline (Source: Ethiopian Railway Corporation). 
Ballast flying is defined as the projection of ballast particles from their resting position as the train moves over the track structure. Ballast flying occurs when a combination of mechanical and aerodynamic forces, generated by the passage of the train, cause ballast particles to overcome gravity [2] [3]. It is a complex interaction of different forces that arise from train aerodynamics, train dynamic load, track structure and the physical property of ballast [3]. Different researchers tried to explain the concept of ballast flying and its causes that lead to the initiation and final projection of the ballast. Full scale experiments on the actual field, wind tunnel test simulation and numerical investigations have revealed the major causes of ballast flying [4] [5].

According to Hayward et al. [6], ballast particle transportation onto the rail head occurs due to an initial suspension of the particle and immediate flight into the path of the wheel. Two mechanisms of ballast levitation can be considered. While the first approach is based on the assumption of a large initial velocity to lift the ballast, the second approach considers a small initial velocity plus in-flight lift due to vertical flow velocity field. Considering the second approach, an initial vertical velocity measured by the geophones $(0.02 \mathrm{~m} / \mathrm{s})$, with a maximum vertical flow velocity field can induce ballast flight [6]. Measurements of sleeper and ballast velocity and acceleration showed that the ballast particles were unlikely to have sufficient velocity to become airborne due to mechanical vibrations alone when train aerodynamics force results in a velocity that is smaller than $0.02 \mathrm{~m} / \mathrm{s}$.

Discrete Element Method is a numerical procedure used to solve problems that exhibit gross discontinuous behavior. This method is capable of analyzing multiple interacting bodies undergoing large dynamic movements. By modeling the individual particles and quantifying their motion, the overall behavior of the granular assembly is simulated implicitly. Interaction of granular materials or rock masses can this way be modeled accurately and realistically since any discontinuous detail can be included in the analysis. Discrete Element Methods have thus been widely applied to model problems with soil and rock mechanics [6] [7] [8]. In the past years, researches on granular medium, especially numerical simulations, yielded significant results which can be applied to railway problems. DEM can be used to analyze a wide variety of mechanical properties of ballast bed (the microstructure of granular materials) that the continuum methods like the Finite Element Modeling (FEM) cannot [9]. For instance, ballast settlement after long cyclic loading, ballast vibration characteristics, breakage characteristics and lateral ballast resistance could favorably be investigated using DEM. In DEM approach, the materials are modeled to have grain to grain contact, as a discrete system of rigid bodies [9] [10].

Particle Flow Code (PFC3D/2D) software is a DEM software based on granular mechanics. It is suitable to analyze granular materials from a micro perspective. It allows users to simulate particles with simple spheres, with the possibilities of establishing complex particle models with combinations of spheres [11]. 
The basic elements in PFC3D include sphere and wall, among which sphere is easier for modeling and can save calculation time. However, sphere cannot represent multi-contact and interlocking characteristic of real ballast; therefore, cluster is used to model ballast by bonding spheres [12] [13] [14]. PFC3D provides two bonding models to make the cluster, a contact-bond model and a parallel-bond model [11] [15] [16]. The contact-bond glue is of a vanishing small size that acts only on the contact points, whereas the parallel-bond is of infinite glue that acts on a circular cross-section placed between spheres, which can represent the effects of additional material (e.g., cementation) deposits after the balls contact. The bond breaks when contact force exceeds bond strength and there is no displacement between spheres when the bond exists [15].

Different researchers have used DEM to study about the mechanical behavior of railway ballast with due considerations of the macroscopic dynamics, particle kinematics, particle breakage and loading behaviors [17] [18] [19]. Thereby they have demonstrated the validity of the DEM technique for modeling railway ballasts. [20] used DEM to simulate the results of triaxial tests on railway ballasts under montonic and cyclic loading conditions. Lu [21] simulated the results of triaxial tests on sand by using DEM software PFC3D with clump particles. Their numerical analyses using the PFC3D software were in good agreement with the measurements. The findings of other researchers [Rad et al.] have also proven the appropriateness of the DEM technique for simulating the behavior of railway ballast. The current computational analyses have thus followed these procedures whose appropriateness has been tested.

This research is helpful in presenting a method of analysis of ballast flying numerically that has not been considered by other researchers in depth. In addition, it gives an insight into the possibility of ballast flying for the ever expanding Ethiopian Railway network.

\section{Materials and Methods}

The material parameters for the numerical analyses are adopted from technical design document of the Chinese Consultant, Addis Ababa-MIESO railway project [22]. There are three major operations in DEM techniques; namely, computation of element contact forces, computation of particle motion and detection of contacts. To complete the operations, the following procedure has to be fulfilled. The procedure for the DEM is summarized as follows.

Prepare ballast particles $\rightarrow$ Gradation $\rightarrow$ Ballast micro parameters $\rightarrow$ Prepare clamps to represent the shape of ballast particle $\rightarrow$ Prepare wall to apply dynamic load $\rightarrow$ Identify type of Test $\rightarrow$ Interpret the result.

One of the basic parameters required for the analysis of ballast flying is the gradation of the ballast (shown in Figure 2), together with the upper and lower bound limits required in the specifications.

The discrete element analysis is performed based on the prevailing particle size distribution of the ballast. Clusters were formed by combining the different particle sizes from the above data using the PFC3D software, which are the basic 
elements for the DEM analyses. The graded sample produced for further DEM analysis is shown in Figure 3.

The input micro-mechanical parameters used to model the behavior of ballast flying including particle to particle and particle to wall friction interactions, particle stiffness and wall stiffness are presented in Table 1. Particle parameters and wall parameters are adopted from the design documents [1] [22] and PFC3D manual [15], respectively.

\section{Results of the Numerical Analyses}

Analysis of ballast particles movement has been performed by using these micromechanics parameters and the aforementioned ballast gradations with the aid of PFC3D. The results of the analyses are illustrated in Figure 4, in terms of the particle velocity, which is the control parameter for the present research.

Table 1. Values of micromechanics parameters [1] [15] [22].

\begin{tabular}{cc}
\hline Micromechanics Parameters & Values \\
Ballast density $\left(\mathrm{kg} / \mathrm{m}^{3}\right)$ & 2600 \\
Ballast particle normal and shear contact stiffness $(\mathrm{N} / \mathrm{m})$ & $1 \times 10^{8}$ \\
Wall normal and shear contact stiffness $(\mathrm{N} / \mathrm{m})$ & $1 \times 10^{9}$ \\
Particle friction coefficient & 0.5 \\
Wall friction coefficient & 0.5 \\
Radius of particles $(\mathrm{mm})$ & $22.4-63$ \\
\hline
\end{tabular}

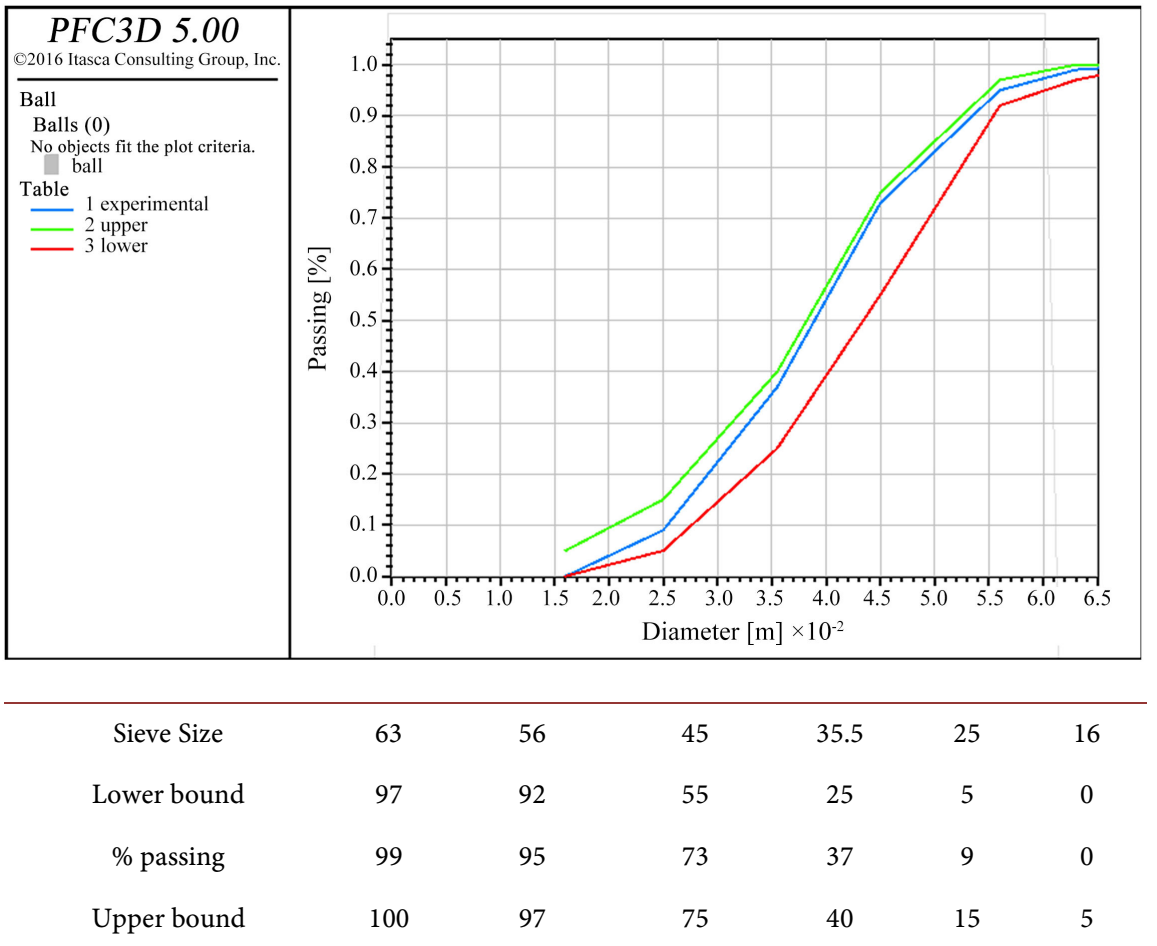

Figure 2. Ballast gradation curve. 


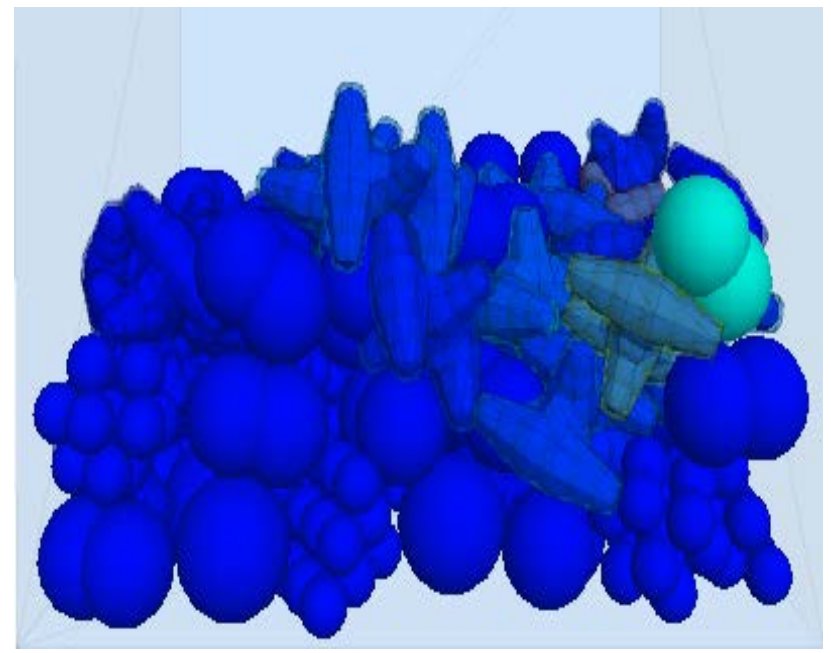

Figure 3. Clusters used in the discrete element analysis.

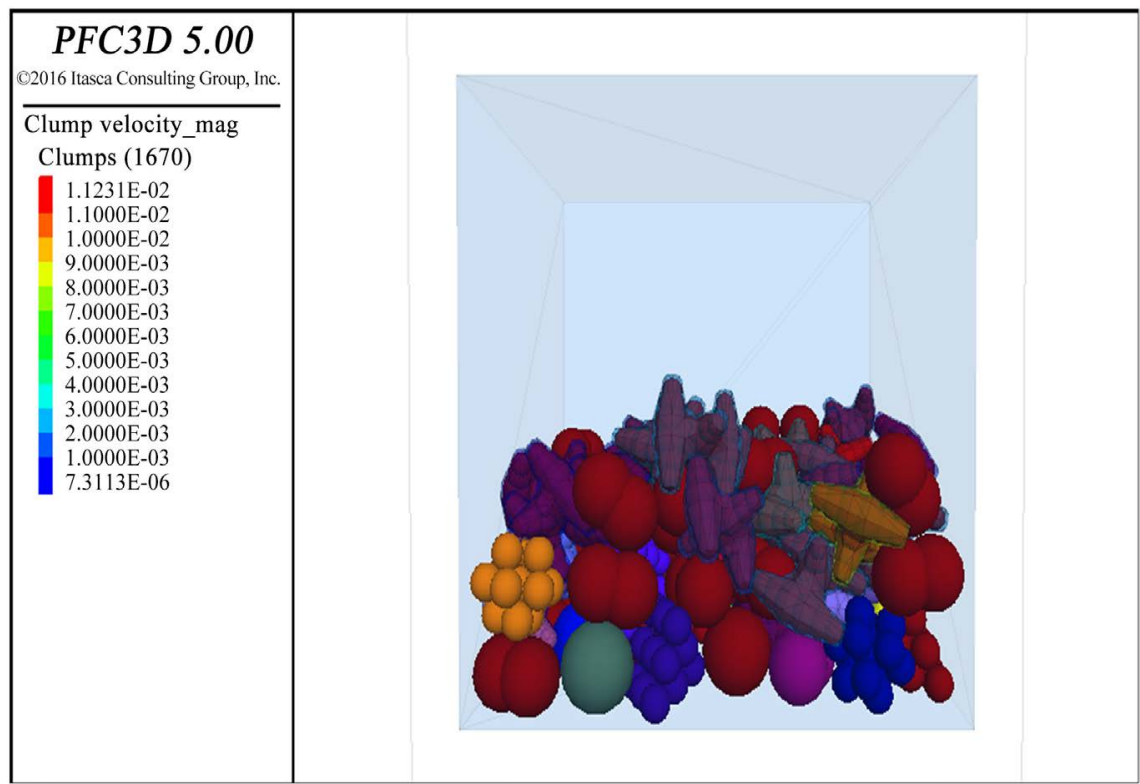

Figure 4. PFC3D modeling result corresponding to the original material.

The maximum vibrational velocity thus obtained is $0.011 \mathrm{~m} / \mathrm{s}$ as shown in the above output graphics. Lifting of ballast due to ballast vibration and wind force created by the train due to aerodynamic force needs higher acceleration and vertical speed of the ballast. The computed vibrational speed is actually less than the value recommended by Quinn [6].

This analysis corresponds to the condition at the construction time when the ballast particles do not change their original size and shape. However, the original condition of the ballast changes with time, which is associated with fouling. Further analysis has thus been carried out by considering ballast fouling due to particle degradation, which is found to be the more critical case that arises after the railway track is in service. Fouling is the term used to indicate contamination of ballast by the presence of fines. The fine particles have small weight surface 
area ratio and their vibrational speed is higher than that of the bigger particles. Due to these reasons, the particles can easily be picked up by aerodynamic forces. A ballast gradation with grain-size diameter of $22.4 \mathrm{~mm}$ is considered as fouling material [23]. Figure 4 shows PFC3D modeling result corresponding to the original material.

The ballast gradation shown in Figure 5 is used to consider the effect of fouling on ballast flying. The gradations are selected based on the design document and consideration of degradation of ballast during service period of time. The fouling material contains more than $5 \%$ clay and silt that come from migration of fines from subgrade [24]. Based on the Fouling Index (FI) proposed by Selig and Waters [25], materials passing the No. 4 sieve $(4.75 \mathrm{~mm})$ are considered "fouling material" whereas European railroads use a grain size diameter of 22.4 $\mathrm{mm}$ as fouling material [23]. Accordingly, the fouled ballast is assumed to have the gradation shown in Figure 5.

The DEM analysis has been performed by applying the above micro-parameters with particle to particle and particle to wall friction coefficient of 0.3 [15] and radius of particles in the ranges 16 to $63 \mathrm{~mm}$. The corresponding results of vibrational speed are thus presented in Figure 6 below.

Due to the presence of fine particles, the maximum vibrational velocity increased to $0.014 \mathrm{~m} / \mathrm{s}$ as shown in Figure 6 in comparison to the previous case. This value is still less than the recommendation of Quinn [6], which ensures that there will be no danger of ballast flying in the selected railway route.

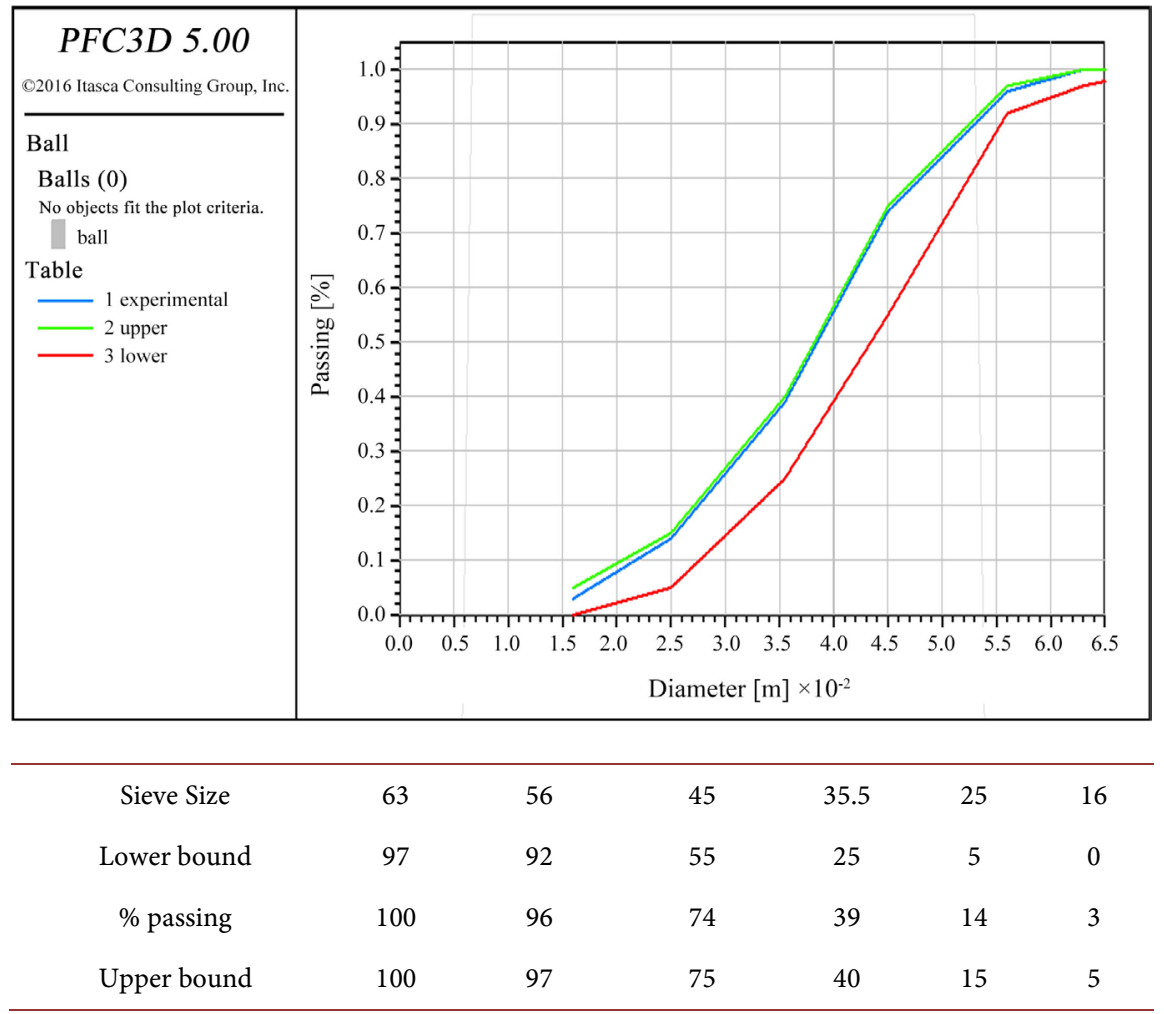

Figure 5. Particle size distribution with consideration of ballast fouling. 


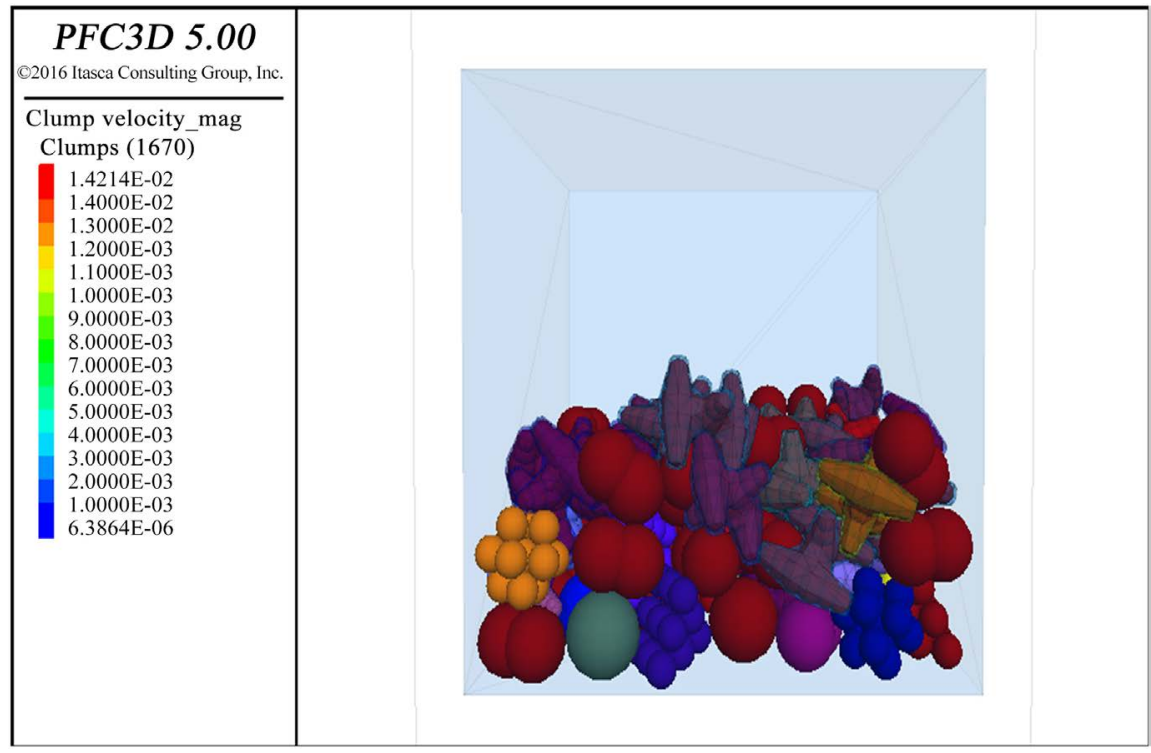

Figure 6. PFC3D modeling result for the case of ballast fouling.

\section{Conclusion}

The present research has focused on assessing the possibility of ballast flying in one of the major railway networks in Ethiopia. From this newly constructed line connecting Ethiopia and Djibouti, the double track portion between Addis Ababa and Adama is chosen for the analysis in order to maximize the effects. Discrete Element Analysis Method has been performed by using the micro-parameters of the ballast properties and wall parameters as inputs for the Particle Flow Code (PFC3D) software. The numerical analyses were performed without and with consideration of ballast fouling after degradation. The corresponding computations gave rise to an extreme ballast vibrational speed of $0.014 \mathrm{~m} / \mathrm{s}$. Since the computed vibrational speed in both cases (with and without considering ballast fouling) is within the recommended limits of literature, ballast flying cannot be considered to be a potential risk within the railway route under investigation.

\section{Acknowledgements}

The authors would like to thank the support of Ethiopian Railway Corporation and Addis Ababa Institute of Technology.

\section{Conflicts of Interest}

The authors declare no conflicts of interest regarding the publication of this paper.

\section{References}

[1] China International Engineering Consulting Corporation (2012) Final Evaluation Report on the Feasibility Study of Addis Ababa/Sebeta-Djibouti Railway Project.

[2] Jacobini, F.B., Tutumluer, E. and Saat, M.R. (2013) Identification of High-Speed Rail Ballast Flight Risk Factors and Risk Mitigation Strategies. 10th World Congress 
on Railway Research, Australia, November 2013.

[3] Jing, G.Q., Zhou, Y.D., Lin, J. and Zhang, J. (2012) Ballast Flying Mechanism and Sensitivity Factors Analysis. Shanghai Jiao Tong University, Shanghai.

[4] Jing, G.Q., Liu, G.X., Lin, J., Martinez, J. and Yin, C.T. (2014) Aerodynamic Characteristics of Individual Ballast Particle by Wind Tunnel Tests. Journal of Engineering Science and Technology Review, 7, 137-142.

https://doi.org/10.25103/jestr.072.21

[5] Kwon, H.B. and Park, C.S. (2019) An Experimental Study on the Relationship between Ballast Flying Phenomenon and Strong Wind under High Speed Train. Korea Railroad Research Institute, Seoul.

[6] Quinn, A.D., Hayward, M., Baker, C.J., Schmid, F., Priest, J.A. and Powrie, W. (2009) A Full-Scale Experimental and Modelling Study of Ballast Flight under High-Speed Trains. University of Birmingham, Birmingham.

https://doi.org/10.1243/09544097JRRT294

[7] Brian Mark Parker (2009) Simulation and Analysis of Particle Flow through an Aggregate Stockpile.

[8] Robertson, D. and Bolton, M.D. (2001) Discrete Element Simulation of Crushable Grains and Soils. Cambridge University Engineering Department, Cambridge.

[9] Gao, L., Luo, Q., Xu, Y., Jing, G.-Q. and Jiang, H.-K. (2015) Discrete Element Method of Improved Performance of Railway Ballast Bed Using Elastic Sleeper. Central South University Press and Springer-Verlag, Berlin.

https://doi.org/10.1007/s11771-015-2860-8

[10] Cholet, C., Oviedo, X. and Gautier, P.E. (2009) Study of the Mechanical Behavior of the Ballast Using Discrete Approach.

[11] Lobo-Guerrero, S. and Vallejo, L.E. (2006) Discrete Element Method Analysis of Railtrack Ballast Degradation during Cyclic Loading. Granular Matter, 8, Article No. 195. https://doi.org/10.1007/s10035-006-0006-2

[12] Huang, H. (2010) Discrete Element Modeling of Railroad Ballast Using Imaging Based Aggregate Morphology Characterization. Dissertation, University of Illinois, Champaign.

[13] Lu, M. and McDowell, G.R. (2006) The Importance of Modelling Ballast Particle Shape in the Discrete Element Method. Journal of Granular Matter, 9, 69-80. https://doi.org/10.1007/s10035-006-0021-3

[14] Lim, W.L. and McDowell, G.R. (2005) Discrete Element Modelling of Railway Ballast. Granular Matter, 7, 19-29. https://doi.org/10.1007/s10035-004-0189-3

[15] Potyondy, D. (2016) Material Modeling Support in PFC 5.0 FISHTank [fistPkg24].

[16] Potyondy, D.O. (2015) The Bonded-Particle Model as a Tool for Rock Mechanics research and Application: Current Trends and Future Directions. Itasca Consulting Group, Inc., Minneapolis. https://doi.org/10.1080/12269328.2014.998346

[17] Ramunas, V., Laurinavicius, A. and Vaitkus, A. (2017) Prediction of Lifespan of Railway Ballast Aggregate According to Mechanical Properties of It. The Baltic Journal of Road and Bridge Engineering, 12, 203-209. https://doi.org/10.3846/bjrbe.2017.25

[18] Yu, Q., et al. (2011) A Validated Discrete Element Modeling Approach for Studying Geogrid-Aggregate Reinforcement Mechanisms. Washington State University, Pullman. https://doi.org/10.1061/41165(397)476

[19] Tutumluer, E., et al. (2007) Discrete Element Modeling of Railroad Ballast Settlement. University of Illinois, Champaign. 
[20] Lu, M. and McDowell, G.R. (2010) Discrete Element Modelling of Railway Ballast Under Monotonic and Cyclic Tri-Axial Loading. Geotechnique, 60, 459-467. https://doi.org/10.1680/geot.2010.60.6.459

[21] Ye, L. (2010) Reconstruction, Characterization, Modeling and Visualization of Inherent and Induced Digital Sand Microstructures. Dissertation, Georgia Institute of Technology, Atlanta.

[22] CREC Addis Ababa-MIESO Railway Project (2015) Testing Report for Stone Ballast.

[23] Stark, T.D., Wilk, S.T., Bruzek, R., Thompson, H.B. and Sussmann, T.R. (2017) Fouled Ballast Definitions and Parameters. American Railway Engineering and Maintenance of Way Association Annual Meeting, Indianapolis, September 2017.

[24] Lonescu, D. (2004) Ballast Degradation and Measurement of Ballast Fouling.

[25] Selig, E.T. and Waters, J.M. (1994) Track Geotechnology and Substructure Management. Thomas Telford Publications, London.

https://doi.org/10.1680/tgasm.20139 